\title{
Iğdır ili yonca alanlarında Hypera postica Gyllenhal (Coleoptera: Curculionidae)'nın larva parazitoiti Bathyplectes curculionis (Thompson) (Hymenoptera: Ichneumonidae) ve parazitlenme oranları
}

\author{
Larval parasitoid Bathyplectes curculionis (Thompson) (Hymenoptera: Ichneumonidae) \\ of alfalfa weevil, Hypera postica Gyllenhal (Coleoptera: Curculionidae) and its \\ parasitism rate in alfalfa fields of Iğdır province, Turkey
}

\author{
Celalettin GÖZÜAÇIK ${ }^{1}$ iD \\ ${ }^{1}$ Iğdır Üniversitesi Ziraat Fakültesi Bitki Koruma Bölümü, Iğdır
}

To cite this article:

Gözüaçık, C. (2019). Iğdır ili yonca alanlarında Hypera postica Gyllenhal (Coleoptera:Curculionidae)'nın larva parazitoiti Bathyplectes curculionis (Thompson) (Hymenoptera: Ichneumonidae) ve parazitlenme oranları. Harran Tarım ve Gıda Bilimleri Dergisi, 23(3): 295-300.

DOI: 10.29050/harranziraat.515168

Address for Correspondence: Celalettin GÖZÜAÇIK

e-mail:

cgozuacik46@gmail.com

Received Date:

20.01.2019

Accepted Date:

09.05.2019

(C) Copyright 2018 by Harran University Faculty of Agriculture. Available on-line at www.dergipark.gov.tr/harranziraat

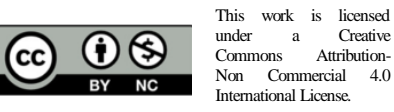

\section{öz}

Çalışma 2014 ve 2015 yıllarında Iğdır ili Merkez, Aralık, Karakoyunlu ve Tuzluca ilçelerinde 61 yonca tarlasında Yonca hortumlu böceği, Hypera postica (Gyllenhal, 1813) (Coleoptera: Curculionidae)'nın larva parazitoitlerini ve parazitlenme oranlarını belirlemek amacıyla ele alınmıştır. Her iki yılda, el ve atrap yardımıyla toplam 9826 larva toplanmış ve laboratuvarda $25^{\circ} \mathrm{C}$ ve $75 \pm 5$ nem ortamında $20 \times 20 \times 30 \mathrm{~cm}$ ebatlarındaki plastik kaplarda kültüre alınmıştır. Larvalar ergin oluncaya kadar taze yonca bitkisiyle beslenmiştir. Çalışmanın sonunda, zararlı H. postica'nın larva parazitoiti olarak Bathyplectes curculionis (Thomson, 1887) (Hymenoptera, Ichneumonidae) türü belirlenmiştir. Parazitlenme oranları ise 2014 ve 2015 yıllarında sırasıyla Merkez ilçede \%12.2 - 11.2, Aralık'ta \%16.8 - 9.8, Karakoyunlu'da \%6.7 17.0 ve Tuzluca'da, \%21.7 - 16.9 olarak bulunmuştur.

Anahtar Kelimeler: Hypera postica, Bathyplectes curculionis, Parazitlenme oranı, Yonca, Iğdır

\section{ABSTRACT}

This study was carried out to identify the parasitoids larvae and parasitism rates of Hypera postica (Gyllenhal, 1813) (Coleoptera: Curculionidae) in 61 alfalfa fields of Central, Aralık, Karakoyunlu and Tuzluca districts of Igdir province in between the years of 2014 and 2015. For both years, a total of 9826 larvae were collected by hand and sweep net and kept at $25 \pm 1{ }^{\circ} \mathrm{C}$ and $75 \pm 5 \% \mathrm{RH}$. in plastic containers $(20 \times 20 \times 30 \mathrm{~cm}$ dimension) in the laboratory. The larvae were fed with fresh alfalfa plants until reach adult stage. As a result of the study, Bathyplectes curculionis (Thomson, 1887) of the family Ichneumonidae of the order Hymenoptera were determined as larval parasitoid of $\mathrm{H}$. postica. The parasitism rates, as 12.2 - 11.2\% in Central, 16.8 - 9.8\% in Aralık, 6.7 - 17.0\% in Karakoyunlu and $21.7-16.9 \%$ in Tuzluca were recorded between two consecutive years, respectively.

Key Words: Hypera postica, Bathyplectes curculionis, Parasitism rates, Alfalfa, Iğdır
Giriş

Yonca (Medicago sativa L.) önemli bir yem bitkisi olup, ülkemizde ve dünyada geniş alanlarda ekimi yapılmaktadır. Yem bitkileri içerisinde en yüksek besin değerine sahiptir. Kuru ve yeşil otu hayvanlar için besleyici olup, vitaminlerce zengindir. Yonca bitkisi yukarıdaki faydalarının yanında yeşil gübre ya da toprak ıslahı amacı ile de yetiştirilmektedir. Aynı zamanda köklerinin derinlere kadar inmesi sonucunda diğer bitkilerinin faydalanmadığı besin maddelerini üst 
katmanlara taşıyarak kendisinden sonra ekilen bitkilere organik madde ve azotça zengin bir toprak bırakmaktadır. Bunun yanında Rhizobium bakterileri ile ortak yaşama girerek havanın serbest azotunu toprağa sağlama yeteneğine de sahiptir (Açıkgöz, 2001). Yoncayı diğer yem bitkilerinden üstün kılan bu özelliklerine ilaveten; uzun ömürlülüğü, vejetasyon döneminde birçok defa biçilebilmesi, adaptasyon yeteneğinin yüksek olması, verim ve besin değerinin yüksekliği, ekim nöbetinde önemli etkinliği ve kimi çeşitlerinin otlatılmaya dayanıklılığıdır (Soya ve ark., 2004). Bu özellikleri nedeniyle yonca bitkisi ülkemizde, yem bitkileri içinde tarımı en fazla yapılan bitki durumundadır (Yolcu ve Tan, 2008). Tüik (2017) verilerine göre, ülkemizde 659432 ha alanda yonca ekilmekte ve 17561190 ton yeşil ot üretilmektedir. Iğdır ilinde ise 34266 ha alanda yonca ekilmekte ve 1833100 ton yeşil ot üretilmektedir. Iğdır ili, Doğu Anadolu Bölgesi illerine göre, farklı iklim ve topografik yapılarından dolayı yıl içinde yonca biçimi ortalama 3-4 defa yapılabilmektedir. Üreticiler için yonca hem kendi hayvanlarının besini olarak hem de üretim fazlasını satarak önemli gelirler elde etmektedir. Ancak, yonca üretimini olumsuz etkileyen birçok böcek bulunmaktadır. Bunların başında Yonca Hortumlu Böceği, Hypera postica (Gyllenhal, 1813) (Coleoptera: Curculionidae) gelmektedir. Asıl zararı birinci biçime kadar olan dönemde larvalar yapmakta ve yonca tarımının yapıldığı birçok yerde yoncada ciddi zararlar oluşturmaktadır (Essig ve Michelbacher, 1933; Clausen, 1977; Steffey ve Armbrust, 1991; Metcalf ve Luckman, 1994; Blodgett ve Lenssen, 2004; Moradi-Vajargah ve ark., 2011). Hypera postica'nın günümüze kadar birçok yumurta, larva ve ergin parazitoitleri belirlenmiştir. Bunlar içerisinde ergin parazitoiti olarak; Microctonus aethiopoides (Hymenoptera, Braconidae), larva parazitoitleri olarak; parazitoit olarak, Bathyplectes curculionis, B. stenostigma (Thomson), ve $B$. anurus (Thomson) türleri belirlenmiştir (Al Ayedh ve ark., 1996; Brewer ve ark., 1997). Yumurta parazitoitleri olarak; Anaphes (=Patasson) luna (Girault) Anaphes conotracheli Girault,

1905,

Anaphes

fuscipennis Haliday 1833 (Hymenoptera: Mymaridae) (TAXAPAD, 2018) ve Fidiobia rugosifrons Crawford (Hymenoptera: Platygastridae) (Niemczyk ve Flessel, 1970; Ellis, 1973; Hogg ve Kingsley, 1983) ve Anaphes sp. near leptoceras (Debauche, 1948) (Gözüaçık ve Pricorp, 2017) belirlenmiştir. Üreticiler, pratikte böceğin zararını engellemek için, insektisit kullanmayı tercih etmektedir. Ancak mücadelede yeterli başarı sağlanılamadığı gibi, kullanılan insektisitler çevreyi kirletmekte, bıraktığı kalıntıyla birlikte hayvanlara besin olarak verilmekte ve üreticiler önemli miktarda ürün kayıpları ile karşı karşıya kalmaktadır. Aynı zamanda, dozunda, zamanında ve ekonomik zarar eşiği dikkate alınmadan kullanılan bu insektisitler doğal dengeyi de olumsuz etkilemektedir.

$\mathrm{Bu}$ çalışma Iğdır ili yonca alanlarında zararlı olan $H$. postica'nın larva parazitoitleri ve parazitlenme oranlarının belirlenmesi amacıyla 2014 ve 2015 yıllarında ele alınmıştır.

\section{Materyal ve Metot}

Çalışmalar 2014 ve 2015 yıllarında Iğdır ili Merkez, Aralık, Karakoyunlu ve Tuzluca ilçelerinde yer alan 61 yonca tarlasında 26.03.2014-7.6.2014 ve 17.3.2015-29.05.2015 tarihleri arasında yoncanın 1. biçimi öncesi yürütülmüştür. Hypera postica larvaları el ve standart atrap $(38 \times 90 \mathrm{~cm})$ yardımıyla her bir tarlanın 10 farklı yerinden 10'ar atrap sallanarak toplanmıştır. Toplanan larvalar içinde yonca bitkisinin olduğu ve üzerlerinde etiket bilgilerinin yazıldığı 20×20×30 cm çapındaki plastik kaplarda laboratuvara getirilmiştir. Larvalar laboratuvarda $25 \pm 2{ }^{\circ} \mathrm{C}$ ve $75 \pm 5$ nem ortamında $20 \times 20 \times 30 \mathrm{~cm}$ çapındaki plastik kaplara her kap içinde 50 larva olacak şekilde kültüre alınmıştır. Larvalar ergin oluncaya kadar taze yonca bitkisiyle beslenmiştir. Kültürler, günlük kontrol edilmiş ve çıkış yapan ergin parazitoitler teşhis ve sayım için içinde \%70 etil alkol bulunan 2x10 kapaklı plastik tüplere alınmıştır. Parazitoitlerin teşhisleri Dr. Janko KOLAROV (Faculty of Pedagogy, University of Plovdiv, 24 
Tsar Assen Str., 4000 Plovdiv, Bulgaria) tarafından yapılmıştır. Parazitlenme oranları ise parazitlenmiş ve parazitlenmemiş larva sayıları oranlanarak elde edilmiştir.

\section{Araştırma Bulguları ve Tartışma}

Iğdır ili yonca alanlarından Hypera postica'nın larvalarından Hymenoptera takımının Ichneumonidae familyasından Bathyplectes curculionis (Thomson, 1887) türü tespit edilmiştir. Bu tür, soliter endoparazit olup, H. postica'nın dünyada en yaygın olarak görülen larva parazitoitlerindendir. B. curculionis, ığdır ilinde yonca alanlarında her iki yılda da $H$. postica larvalarından elde edilmiş olup, parazitlenme oranları Çizelge 1 ve 2'de verilmiştir.

Çizelge 1 incelendiğinde, Iğdır ili Merkez ilçede 2014 yılı çalışmalarında, 9 farklı yonca tarlasından 547 H. postica larvası kültüre alınmıştır. Bu larvalardan 67 B. curculionis ergini elde edilmiş ve ortalama \%12.2 parazitlenmenin olduğu belirlenmiştir. Merkez ilçede çalışmanın yürütüldüğü alanlarda en yüksek parazitlenme \%33.0 oranıyla Çalpala'da görülmüş, Hakmehmet1'de ise parazitlenmeye rastlanılmamıştır. Aralık ilçesinde yapılan çalışmalarda 11 farklı yonca tarlasında toplam 1710 larva toplanmış ve bu larvalardan 288 B. curculionis ergini alınmıştır. Ortalama parazitlenme oranı ise, $\% 16.8$ olarak belirlenmiştir. Aralık ilçesinde en yüksek parazitlenme \%57.5 ile Emince'de görülmüş, Hacıağa, Aşağı Aratan ve Ortaköy'de ise parazitlenmeye rastlanılmamıştır. Karakoyunlu ilçesinde 5 farklı yonca tarlasında toplam 4185 larva toplanmış ve bu larvalardan $280 \quad B$. curculionis ergini elde edilmiştir. Ortalama parazitlenme oranı, \%6.7 olarak belirlenmiştir. Karakoyunlu ilçesinde en yüksek parazitlenme \%15.2 ile Bulakbaşı1'de görülmüş, diğer alanlarda ise parazitlenme oranı \%5.5 ile \%8,0 arasında değişmiştir. Tuzluca ilçesinde 4 farklı yonca tarlasında toplam 251 larva toplanmış ve bu larvalardan 57 B. curculionis ergini elde edilmiştir. Ortalama parazitlenme oranı, \%21.7 olarak belirlenmiştir. Tuzluca ilçesinde en yüksek parazitlenme \%29.8 ile Eğrekdere'de bulunmuş, diğer alanlarda ise parazitlenme oranı \%5.8 ile \%25.0 arasında değişmiştir.

Çizelge 1. Hypera postica'nın 2014 yılı Iğdır ili Merkez, Aralık, Karakoyunlu ve Tuzluca ilçelerindeki parazitlenme oranları (\%)

Table 1. Parasitism rates (\%) of Hypera postica in Central, Aralık, Karakoyunlu and Tuzluca districts of Iğdır province in 2014

\begin{tabular}{|c|c|c|c|}
\hline \multicolumn{4}{|c|}{ MERKEZ } \\
\hline & $\begin{array}{c}\text { Toplam } \\
\text { larva } \\
\text { sayısı }\end{array}$ & $\begin{array}{c}\text { Ergin } \\
\text { parazitoit } \\
\text { sayısı }\end{array}$ & $\begin{array}{c}\text { Parazitlenme } \\
\text { oranı (\%) }\end{array}$ \\
\hline Hakmehmet & 39 & 4 & 10.3 \\
\hline Sarıçoban & 24 & 1 & 4.2 \\
\hline Aliköse & 200 & 14 & 7.0 \\
\hline Çalpala & 106 & 35 & 33.0 \\
\hline Aşağı Çarıkçı & 26 & 1 & 3.8 \\
\hline Melekli & 12 & 3 & 25.0 \\
\hline Yaycı & 70 & 7 & 10.0 \\
\hline Kuzugüden & 43 & 2 & 4.7 \\
\hline Hakmehmet1 & 27 & 0 & 0.0 \\
\hline Toplam & 547 & 67 & 12.2 \\
\hline \multicolumn{4}{|c|}{ ARALIK } \\
\hline & $\begin{array}{c}\text { Toplam } \\
\text { larva } \\
\text { sayısı }\end{array}$ & $\begin{array}{c}\text { Ergin } \\
\text { parazitoit } \\
\text { sayısı }\end{array}$ & $\begin{array}{c}\text { Parazitlenme } \\
\text { oranı (\%) }\end{array}$ \\
\hline Emince & 153 & 88 & 57.5 \\
\hline Hacıağa & 7 & 0 & 0.0 \\
\hline Yukarı çiftlik & 114 & 23 & 20.2 \\
\hline Aşağı aratan & 2 & 0 & 0.0 \\
\hline Ramazankent & 314 & 46 & 14.6 \\
\hline Ortaköy mah. & 151 & 1 & 0.7 \\
\hline Gödekli & 162 & 41 & 25.3 \\
\hline Hacıağa & 51 & 21 & 41.2 \\
\hline Aşağı Çiftlik & 229 & 64 & 27,9 \\
\hline Ortaköy & 36 & 0 & 0.0 \\
\hline Aras Mah. & 491 & 4 & 0.8 \\
\hline Toplam & 1710 & 288 & 16.8 \\
\hline \multicolumn{4}{|c|}{ KARAKOYUNLU } \\
\hline & $\begin{array}{r}\text { Toplam } \\
\text { larva }\end{array}$ & $\begin{array}{r}\text { Ergin } \\
\text { parazitoit }\end{array}$ & $\begin{array}{r}\text { Parazitlenme } \\
\text { oranı (\%) }\end{array}$ \\
\hline & sayısı & sayısı & \\
\hline Karakoyunlu & 1105 & 69 & 6.2 \\
\hline Bulakbaşı & 1880 & 104 & 5.5 \\
\hline Bulakbaşı-1 & 270 & 41 & 15.2 \\
\hline Gacer & 594 & 39 & 6.6 \\
\hline Yukarı Alican & 336 & 27 & 8.0 \\
\hline Toplam & 4185 & 280 & 6.7 \\
\hline \multicolumn{4}{|c|}{ TUZLUCA } \\
\hline & $\begin{array}{l}\text { Toplam } \\
\text { larva }\end{array}$ & $\begin{array}{c}\text { Ergin } \\
\text { parazitoit }\end{array}$ & $\begin{array}{c}\text { Parazitlenme } \\
\text { oranı (\%) }\end{array}$ \\
\hline & sayısı & sayısı & \\
\hline Yukarı mah. & 52 & 3 & 5.8 \\
\hline Eğrekdere & 121 & 36 & 29.8 \\
\hline Tuzluca & 68 & 17 & 25.0 \\
\hline Karabulak & 10 & 1 & 10.0 \\
\hline Toplam & 251 & 57 & 21.7 \\
\hline
\end{tabular}


Çizelge 2. Hypera postica'nın 2015 yılı Iğdır ili Merkez, Aralık, Karakoyunlu ve Tuzluca ilçelerindeki parazitlenme oranları (\%)

Table 2. Parasitism rates (\%) of Hypera postica in Central, Aralık, Karakoyunlu and Tuzluca districts of Iğdır province in 2015

\begin{tabular}{|c|c|c|c|}
\hline \multicolumn{4}{|c|}{ MERKEZ } \\
\hline & $\begin{array}{l}\text { Toplam } \\
\text { larva sayısı }\end{array}$ & $\begin{array}{l}\text { Ergin } \\
\text { parazitoit } \\
\text { sayısı }\end{array}$ & $\begin{array}{l}\text { Parazitlenme } \\
\text { oranı (\%) }\end{array}$ \\
\hline Kazancı & 29 & 3 & 10.3 \\
\hline Hakmehmet & 39 & 4 & 10.2 \\
\hline Sarıçoban & 24 & 1 & 4.2 \\
\hline Aliköse & 200 & 14 & 7.0 \\
\hline Çalpala & 106 & 35 & 33.0 \\
\hline Aşağı Çarıkçı & 26 & 1 & 3.8 \\
\hline Yukarı Çarıkçı & 65 & 2 & 3.2 \\
\hline Yaycı & 70 & 7 & 10.0 \\
\hline Kuzugüden & 43 & 2 & 4.7 \\
\hline Hakmehmet & 27 & 0 & 0.0 \\
\hline Melekli & 12 & 3 & 25.0 \\
\hline Toplam & 641 & 72 & 11.2 \\
\hline \multicolumn{4}{|c|}{ ARALIK } \\
\hline & $\begin{array}{l}\text { Toplam } \\
\text { larva sayısı }\end{array}$ & $\begin{array}{l}\text { Ergin } \\
\text { parazitoit } \\
\text { sayısı } \\
\end{array}$ & $\begin{array}{l}\text { Parazitlenme } \\
\text { oranı (\%) }\end{array}$ \\
\hline $\begin{array}{l}\text { Yukarı } \\
\text { çamurlu }\end{array}$ & 343 & 80 & 23.3 \\
\hline Tazeköy & 249 & 5 & 2.0 \\
\hline Ramazankent & 188 & 16 & 8.5 \\
\hline Taşburun & 17 & 5 & 29.4 \\
\hline Aşağı çiftlik & 35 & 1 & 2.9 \\
\hline Gödekli & 36 & 16 & 44.4 \\
\hline Ortaköy & 48 & 0 & 0.0 \\
\hline Hacıağa & 170 & 15 & 8.8 \\
\hline /Aralık & & & \\
\hline $\begin{array}{l}\text { Yukarı } \\
\text { topraklı }\end{array}$ & 95 & 4 & 4.2 \\
\hline Babacan & 345 & 7 & 2,0 \\
\hline Toplam & 1528 & 149 & 9.8 \\
\hline \multicolumn{4}{|c|}{ KARAKOYUNLU } \\
\hline & $\begin{array}{l}\text { Toplam } \\
\text { larva sayısı }\end{array}$ & $\begin{array}{l}\text { Ergin } \\
\text { parazitoit } \\
\text { sayısı }\end{array}$ & $\begin{array}{l}\text { Parazitlenme } \\
\text { oranı (\%) }\end{array}$ \\
\hline Karakoyunlu & 62 & 7 & 11.3 \\
\hline Bulakbaşı & 73 & 18 & 24.7 \\
\hline Orta Alican & 44 & 5 & 11.4 \\
\hline Cennetabat & 39 & 4 & 10.3 \\
\hline Yukarı Alican & 8 & 0 & 0.0 \\
\hline Gökçeli & 30 & 10 & 33.3 \\
\hline Gacer & 73 & 12 & 16.4 \\
\hline Toplam & 329 & 56 & 17.0 \\
\hline \multicolumn{4}{|c|}{ TUZLUCA } \\
\hline & $\begin{array}{l}\text { Toplam } \\
\text { larva sayısı }\end{array}$ & $\begin{array}{l}\text { Ergin } \\
\text { parazitoit } \\
\text { sayısı }\end{array}$ & $\begin{array}{l}\text { Parazitlenme } \\
\text { oranı (\%) }\end{array}$ \\
\hline Eğrekdere & 118 & 26 & 22.0 \\
\hline Karabulak & 223 & 38 & 17.0 \\
\hline Kamışlı & 171 & 18 & 10.5 \\
\hline Tuzluca & 114 & 24 & 21.1 \\
\hline Toplam & 626 & 106 & 16.9 \\
\hline
\end{tabular}

Çizelge 2 incelendiğinde, Iğdır ili Merkez ilçede 2015 yılı çalışmalarında, 11 farklı yonca tarlasından $641 \mathrm{H}$. postica larvası kültüre alınmıştır. Bu larvalardan 72 B. curculionis ergini elde edilmiş ve ortalama \%11.2 parazitlenmenin olduğu belirlenmiştir. Merkez ilçede çalışmanın yürütüldüğü alanlarda en yüksek parazitlenme \%33.0 oranıyla Çalpala'da görülmüş, Hakmehmet'de ise parazitlenmeye rastlanılmamış diğer alanlarda ise \%3.2 ile \%25.0 arasında değişmiştir. Aralık ilçesinde yapılan çalışmalarda 10 farklı yonca tarlasında toplam 1528 larva toplanmış ve bu larvalardan 149 B. curculionis ergini alınmıştır. Ortalama parazitlenme oranı ise, \%9.8 olarak belirlenmiştir. Aralık ilçesinde en yüksek parazitlenme \%44.4 ile Gödekli'de görülmüş, Ortaköy'de ise parazitlenmeye rastlanılmamış, diğer alanlarda ise \%2.0 ile \%29.4 arasında değişmiştir. Karakoyunlu ilçesinde 7 farklı yonca tarlasında toplam 329 larva toplanmış ve bu larvalardan 56 B. curculionis ergini elde edilmiştir. Ortalama parazitlenme oranı, \%17.0 olarak belirlenmiştir. Karakoyunlu ilçesinde en yüksek parazitlenme \%33.3 ile Gökçeli'de görülmüş, diğer alanlarda ise parazitlenme oranı \%10.3 ile \%27.7 arasında değişmiş Yukarı Alican'da ise larva sayısı düşük bulunmuş ve parazitlenme oranı belirlenmemiştir. Tuzluca ilçesinde 4 farklı yonca tarlasında toplam 626 larva toplanmış ve bu larvalardan 106 B. curculionis ergini elde edilmiştir. Ortalama parazitlenme oranı, \%16.9 olarak belirlenmiştir. Tuzluca ilçesinde en yüksek parazitlenme \%22.0 ile Eğrekdere'de bulunmuş, diğer alanlarda ise parazitlenme oranı \%10.5 ile \%21.1 arasında değişmiştir.

Iğdır ilinde her iki yılda yapılan çalışmalar değerlendirildiğinde 2014 yılında toplam 6693 larva kültüre alınmış ve bu larvalardan 692 parazitoit ergini elde edilmiş ve parazitlenme oranı \%10.3 olarak belirlenmiştir. İlçelerdeki en yüksek parazitlenme \%21.7 oranıyla Tuzluca'da, en düşükte \%6.7 oranıyla Karakoyunlu'da tespit edilmiştir. Çalışmaların ikinci yılında ise, toplam 3124 larva kültüre alınmış ve bu larvalardan 383 parazitoit ergini elde edilmiş ve parazitlenme 
oranı \%12.3 olarak belirlenmiştir. İlçelerdeki en yüksek parazitlenme $\% 17.0$ oranıyla Karakoyunlu'da, en düşükte $\% 9,8$ oranıyla Aralık'ta kaydedilmiştir. İlçelerdeki parazitlenme oranlarındaki bu farklıığın, yonca alanlarının farklı ekosistemlerde bulunduğu, özellikle polikültür tarımın yoğun olarak yapıldığı ve biyoçeşitliliğin zengin olduğu alanlarda parazitlenme oranlarının yüksek olduğu görülmüştür. Parazitlenme oranlarının düşük olduğu ekosistemlerde ise yoncanın geniş alanlarda bitişik tarlalar olacak şekilde ekildiği ve bu alanlarda insektisit uygulama sayısının fazla olması ( 2 ya da 3 defa) ve tavsiye dışı geniş spektrumlu insektisitlerin tercih edilmesinden kaynaklandığı, düşünülmektedir. Iğdır ilinde her iki yılda da $H$. postica larvalarındaki parazitlenme oranlarında farklılıklar bulunmuştur. Kuhar ve ark. (2000), Virginia'da önemli bir zararlı konumunda olan $H$. postica larvalarının, Bathyplectes anurus (Hymenoptera: Ichneumonidae) tarafından \%36-92 oranları arasında parazitlenebildiğini bildirmişlerdir. Kingsley ve ark., (1993), B. curculionis ve $B$. anurus'un \%21 oranında yonca hortumlu böceğinde ölümlere neden olabildiğini belirtmişlerdir. Efil (2018)'in Diyarbakır, Mardin ve Şanlıurfa'da yaptığı çalışmada parazitlenme oranının genelde düşük olduğunu, en fazla parazitlenme oranının \%22.22 ile Mardin (Kızıltepe) lokasyonunda bulunduğunu, Diyarbakır (Merkez) ve Şanlıurfa (Akçakale) lokasyonlarındaki parazitlenme oranlarının \%3.75 ile 0.55 arasında değiştiğini bildirmiştir. Davis (1974) B. curculionis'in yonca hortumlu böceği larvalarını \%63'e kadar parazitleyebildiğini bildirmiştir.

\section{Sonuçlar}

Iğdır ili Merkez, Aralık, Karakoyunlu ve Tuzluca ilçelerindeki yonca tarlalarında 2014 ve 2015 yıllarında yapılan çalışmalarda $H$. postica'nın birinci yıl 30, 2. yıl 32 yonca tarlasından toplam 9826 larvaları toplanmıştır. Bu larvalardan Bathyplectes curculionis parazitoiti elde edilmiştir. Parazitlenme oranları ise 2014 ve 2015 yıllarında sırasıyla Merkez ilçede \%12.2 - 11.2, Aralık'ta
\%16.8 - 9.8, Karakoyunlu'da \%6.7 - 17.0 ve Tuzluca'da, \%21.7 - 16.9 olarak bulunmuştur. Yonca bitkisinde asıl zararı $H$. postica larvaları yapmakta ve bu zarar ilk biçimde elde edilecek üründe önemli kayıplarına neden olmaktadır. Üreticiler, bu zararı önlemek için yoğun olarak kimyasal mücadeleye başvurmaktadır. Bu da doğal dengenin zararlı lehinde bozulmasına neden olmaktadır. Çalışmalarda kimyasalların daha az uygulandığı ve biyo-çeşitliliğin zengin olduğu alanlarda parazitoitin daha etkin olduğu görülmektedir. Ayrıca, çalışmalarda parazitlenme oranlarının aynı ekosistem içerisinde neredeyse tarladan tarlaya değiştiği görülmüş, bu da üreticilerin mücadeleyi farklı zamanlarda ve farklı sayılarda bilinçsizce yaptığı anlaşılmıştır. Bundan dolayı, üreticilerin zararlıyı kontrol etmede, mücadeleye entegre mücadele çerçevesinde yaklaşması ve bu konuda uygulamalı çiftçi eğitimlerin daha sık ve etkin bir şekilde yapılması entegre mücadeleyi destekleyecek eğitimlerin verilmesinin (mutlu ve ark., 2016) yararlı olacağı kanaatine varılmıştır.

\section{Ekler}

Bu makale, Uluslararası Katılımlı Türkiye 6. Bitki Koruma Kongresinde (5-8 Eylül 2016, Konya), kısmen özet olarak sunulmuştur.

\section{Kaynaklar}

Açıkgöz, E. (2001). Yem Bitkileri. Uludağ Üniversitesi Güçlendirme Vakfı Yayın no:182. Bursa.

Al Ayedh, H.Y., Kondratieff, B.C., Blodgett, S.L., Peairs, F.B. (1996). Evaluation of Hymenopterous Biological Control Agents of the Alfalfa Weevil Larvae Hypera postica (Coleoptera: Curculionidae) in Northcentral Colorado. Journal of the Kansas Entomological Society Vol. 70, No. 3 (Jul., 1997), pp. 197-202

Blodgett, S.L., Lenssen, A.W. (2004). Distribution of alfalfa weevil (Coleoptera: Curculionidae) larvae among postcutting locations. Journal of Economic Entomology, 97:1319-1322

Brewer, M. J., Donahue, J.D., Morrison, E.J. (1997). Bathyplectes Parasitoids (Hymenoptera: Ichneumonidae) of Alfalfa Weevil, Hypera postica, (Coleoptera: Curculionidae) in Wyoming. Journal of the Kansas Entomological Society. Vol. 69, No. 4 (Oct., 1996), pp. 326-336. 
Clausen, C.P. (Ed.) (1977). Introduced parasites and predators of arthropod pests and weeds-alfalfa weevil. US Dep. Agric. Handbook No. 480, pp. 266271.

Davis, D.W. (1974). Parasite-prey ratios among alfalfa weevil larvae of northern Utah. Environmental Entomology, 3: 1031-1032.

Efil, L. (2018). Diyarbakır, Şanlıurfa ve Mardin Illeri Yonca Alanlarında Zararlı Yonca Hortumlu Böceği Hypera variabilis (Herbst, 1795) (Coleoptera: Curculionidae)'nin Zarar Durumu ve Larva Parazitoiti Bathyplectes curculionis (Thomson, 1887) ve Parazitlenme Oranları. Türk Tarım ve Doğa Bilimleri Dergisi, 5(1): 86-89

Ellis, C.R. (1973). Parasitism of Hypera postica Eggs at Guelph, Ontario, by Patasson luna and Fidiobia rugosifrons. Journal of Economic Entomology, 66(5)1059-1062.

Essig, E.O., Michelbacher, A.E. (1933). The alfalfa weevil. Bulletin of the California Agricultural Experiment Station, 567, 99 pp.

Gözüaçık, C., Pricorp, E. (2017). First record for an egg parasitoid of Hypera postica (Gyllenhal, 1813) (Coleoptera: Curculionidae) from Turkey. II International Iğdır Symposium, 9-11 October 2017, p. 39, Iğdir.

Hogg, D.B., Kingsley, P.C. (1983). Parasitization by Patasson luna (Hymenoptera: Mymaridae) of alfalfa weevil (Coleoptera: Curculionidae) eggs laid in green alfalfa stems and in litter. Journal of Economic Entomology, 76:54-56

Kingsley, P.C., Brayn, M.D., Day, W.H., Burger, T.L., Dysart, R.J., Schwable, C.P. (1993). Alfalfa weevil (Coleoptera: Curculionidae) biological control: spreading the benefits. Environmental Entomology, 22(6): 1234-1250.
Kuhar, T.P., Youngman, R.R., Laub, C.A. (2000). Alfalfa Weevil (Coleoptera: Curculionidae) Population Dynamics and Mortality Factors in Virginia. Environmental Entomology. 29 (6): 1295-1304.

Metcalf, R.L., Luckman, W.H. (1994). Introduction to insect pest management. 3rd ed. Wiley, New York.

Moradi-Vajargah, M., Golizadeh, Ali. Rafiee-Dastjerdi, Hoosang. Zalucki, M.P., Hassanpour, M., Naseri, B. (2011). Population Density and Spatial Distribution Pattern of Hypera postica (Coleoptera: Curculionidae) in Ardabil, Iran. Notulae Botanicae Horti Agrobotanici Cluj-Napoca. 39(2): 42-48.

Mutlu, Ç., Duman, M., Karaca, V., Bayram, Y., Sıray, E., Kan, M. (2016). Kışlamış Süne Ergin Mücadelesinde Çiftçi Bilinç Düzeyi Örnek Çalışması: Güneydoğu Anadolu Bölgesi. Türk Tarım ve Doğa Bilimleri Dergisi 3(4): 280-287

Niemczyk, H.D., Flessel, J.K. (1970). Population dynamics of alfalfa seed weevil in eggs in Ohio. Journal of Economic Entomology. 63(1):242-247.

Soya, H, R. Avcıoğlu ve Geren, H. (2004). Yem Bitkileri. Hasad Yayıncılık, $223 \mathrm{~s}$.

Steffey, K.L., Armbrust, E.J. (1991). Pest management systems for alfalfa insects, pp. 475-504. In D. Pimentel (ed.), CRC handbook of pest management in agriculture (2nd Ed.). CRC Press. Boca Raton, Fl.

TAXAPAD,

(2018). http://www.taxapad.com/local.php?newwolp=8074 0372 (Erişim tarihi: 14.12.2018).

Yolcu, H., Tan, M. (2008). Ülkemiz yem bitkileri tarımına genel bir bakış. Tarım bilimleri Dergisi, 14 (3): 303312.

TUiK, (2017). Bitkisel üretim istatistikleri. https://biruni.tuik.gov.tr/medas/?kn=92\&locale=tr (Erişim tarihi: 14.12.2018). 